\title{
INTEGRATED PLANNING AS A TOOL FOR SUSTAINABLE DEVELOPMENT OF THE REGIONS
}

\author{
Borislav Borisov ${ }^{1}$, Evelina Parashkevova ${ }^{2 *}$, Hristo Sirashki ${ }^{3}$, Mariela Stoyanova ${ }^{4}$ \\ ${ }^{1}$ Prof. DsC, D. A. Tsenov Academy of Economics - Svishtov, BULGARIA, \\ b.borissov@uni-svishtov.bg \\ ${ }^{2}$ Assoc. Prof. PhD, D. A. Tsenov Academy of Economics - Svishtov, BULGARIA, \\ e.parashkevova@uni-svishtov.bg \\ ${ }^{3}$ Assoc. Prof. PhD, D. A. Tsenov Academy of Economics - Svishtov, BULGARIA, \\ h.sirashki@uni-svishtov.bg \\ ${ }^{4}$ Assist. Prof. PhD, D. A. Tsenov Academy of Economics - Svishtov, BULGARIA, \\ m.stoyanova@uni-svishtov.bg \\ ${ }^{*}$ Corresponding Author
}

\begin{abstract}
The article discusses matters regarding the integrated approach for achieving balanced and sustainable regional development, as part of the support mechanisms of the European Union countries. It intends to address key weaknesses in the effective achievement of the goals of cohesion policy in EU. The current focus of resources on a general principle not only does not lead to cohesion, but also deepens the disparities. The aim of the article is to bring out perspectives and to identify challenges for implementation of integrated planning approach in Bulgaria. The object of research is the integrated territorial investment's approach, and the subject is its influence on the sustainable regional development. Scientific literature review regarding adoption of integrated territorial investments has been made. Based on identified practical experience, challenges to the planning process in the context of the pan-European regional policy, on the one hand, and the existing planning practice on the other, have been outlined. Issues related to the expected integrated solutions to various regional problems, because of the application of the new, more flexible planning approach, oriented to the common territorial interest, have been studied. Special attention is paid to sustainable development and the role of the planning function for its achievement. The integrated territorial investments are analyzed as a mechanism for integrated local development with the wide participation of the stakeholders and the possibility for effective and efficient implementation within the programming period 2021-2027.

Based on deduction, induction and content analysis of documents, the prospects for the implementation of integrated territorial investments are outlined as a tool for achieving sustainability, balance and growth.
\end{abstract}

Keywords: planning, integrated territorial investments, sustainable regional development

\section{LITERATURE REVIEW OF MODERN APPROACHES FOR REGIONAL PLANNING AND DEVELOPMENT}

Regional development at European Union level faces a number of challenges, mainly due to the ineffective implementation of the initially adopted approach to directing financial resources to less developed regions. Not only the objectives of the Union's cohesion policy are not being achieved, but even the disparities are growing. A number of authors (Tödtling \& Trippl , 2005) (Barca, McCann, \& Rodríguez-Pose, 2012) outline in 
some of their scientific works a tendency towards deepening economic disparities between EU countries and between their regions. Intervention instruments are not achieving the expected sustainable results in terms of economic growth. The policy adopted so far to direct resources in general has proved ineffective.

This fact necessitates the recognition and applying of a new paradigm of regional planning, based on the use of the specific potential of a certain territory (Territorial outlook, 2001). It is based on principles related to improving the own capabilities of territorial units, sustainable development and creating more responsible governance.

Researchers such as Barca draw attention to the fact that, in order to achieve better results in terms of convergence between regions in the Union, interventions need to be defined not by administrative boundaries but by identified common challenges and development potential (Barca, 2009). This concept focuses on providing support for the endogenous potential of a given territory in the end through targeted cross-sectorial actions and a multi-level governance system. (Regions matter: Economic recovery, innovation and sustainable growth, 2009). The new approach includes close dialogue and cooperation between the participants working at different levels, incl. governing bodies at national and local level, NGOs, business structures, academic community. It also combines external expertise and local resources. Adapting public policies to the needs of the region must have lasting consequences for the local population. The aim is to help achieve both European and national goals, thanks to the proper use of internal development factors such as infrastructure, culture, governance, climate (Scenarios for Integrated Territorial Investments , 2015).

Researchers in the field of integrated planning point out in their works the implementation of the integrated territorial approach as an opportunity to overcome the accumulated challenges regarding the strong economic division between the regions (Bachtler, Mendez, \& Wishlade, 2016) (Davies, Ferry, \& Vironen, 2016). Along with the advantages, a possible risk to the applying of the approach has been identified, mainly caused by the different way of functioning of the institutions in the individual countries. For this purpose, it is recommended to develop and use a mechanism for cost regulation and for implementation evidence.

Strategies that promote vertical and horizontal cooperation, territorial integration and knowledge sharing are an integral part of the integrated approach. Although there is a long and ongoing debate at EU level on how to promote better cooperation and integration between political sectors, initial findings provide evidence to support that the integration of interventions - often the most practical and achievable at locally level. The existence of a territorial strategy together with a collective body engaged in regulating the application of the integrated approach are the two main conditions for the implementation of integrated territorial investment (ITI) concepts. The latter are a specific tool for intervention at regional level, typical of the new approach to planning in the EU.

For the past programming period 2014-2020, most of the member states of the Union adopt and implement ITI in order to achieve better results in terms of achieving cohesion between the regions and to promote their sustainable development. Zwet, Miller, Gross, Faludi, Andreas, Peyrony, Czischke, Pascariu were among the first to study the expected added value that integrated territorial investment would bring to the implementation of the Community's cohesion policy, outlining the potential benefits of increasing the influence of local decision-making power (Van Der Zwet, Miller, \& Gross, 2014) (Faludi \& Peyrony, 2011) (Czischke \& Pascariu, 2015). There are also some challenges, such as the difficult task of creating structures and implementation mechanisms that adequately meet the expectations of local actors, but also adhere to regulatory requirements. Other issues that are identified are related to local capacity and questions about how the thematic orientation of the results is aligned with the territorially limited approaches.

Based on the experience gained, albeit for a short period, a number of researchers critically analyze the real effects of the implementation of ITI in some European countries and give recommendations for their future implementation (Ferry, Kah, \& Bachtler, 2018) (Van Der Zwet, Bachtler, Ferry, McMaste, \& Miller, 2017) (Kociuba, 2018) (Gaman, et al., 2015) (Trusculaski, 2020). A common statement is that through integrated territorial investments, administrative units working together learn to act more dynamically for their development. They begin to cooperate by solving problems, not as before - competing for resources. In general, surveys show that in most Member States there was a significant adoption of territorial strategies during the period. Many of these planning documents are new, and territorial provisions encourage innovation and adaptation, both in thinking and in practice. Using the ITI as a tool for intervention in the regions, local governments not only have the opportunity to implement integrated projects, but also to combine activities funded by different European funds.

Benefit from the implementation of ITI from a strategic point of view can be sought in increasing the administrative capacity to achieve integrated territorial development. Assuming that integrated territorial 
investment increases the role of local authorities, NGOs and other regional authorities, this could in the end help to expand the capacity to carry out territorial development activities (Scenarios for Integrated Territorial Investments, 2015) .

In the EU countries that have adopted the use of ITI as a tool for influencing the regions, it is common practice to create an alliance between territorial units with a common endogenous potential, thus taking an institutionalized form of cooperation. In most cases, the creation of unions was based on two models of territorial governance, namely (Kociuba, 2018):

1) An "intermediate" model, usually in the form of an agreement setting up an alliance to absorb funds.

2) A "cooperation" model, in which the union is a natural continuation of earlier cooperation, usually in the form of an association.

It is difficult to say definitively which form of unification is more effective, but based on current conditions, the "cooperation" model shows better results.

In his report, M. Ferry makes an in-depth analysis of the effect of the implementation of ITI in the EU during the programming period 2014-2020, setting out some key recommendations for overcoming identified weaknesses, namely (Ferry M. , 2019):

- Need for capacity building;

- Achieving proportionality;

- Achieving timeliness of actions;

- Mobilization of beneficiaries in the development of project proposals;

- Monitoring and evaluation;

- Achieving longer-term sustainability.

\section{CHALLENGES TO THEORY AND PRACTICE OF PLANNING}

The science of planning is constantly evolving, offering new concepts, models and solutions that are tested, implemented or rejected by practice, looking for the most appropriate ones. As public claims on public authorities grow steadily and the economic environment becomes more dynamic, planning seeks to be adequate to these challenges and the requirements for achieving social progress. The fact is that planning has its critics. In countries with developed market economies, they expressed doubts that planning could respond to changes in the turbulent environment, and in the former socialist countries - that the centrally planned economy is to blame for the economic backwardness of this group of countries compared to the capitalist one. Both may have their reasons for being frustrated with planning, but a closer look at the specific issues may suggest that they are not due to the nature of planning as a management tool, but to its application in different countries and by different countries governing bodies. For example, Zack Taylor argues that the question of how to explain differences in planning traditions, practices, styles and policies has long been before scientists (Taylor, 2013) and introduces the concept of "planning culture". Newman and Thornley, in their 1996 book Urban Planning in Europe, also attempt to explain the differences in planning patterns across countries by highlighting five European planning families they call the British, Napoleonic, Germanic, Nordic and East European (Newman \& Thornley, 1996). They differ in whether control is directive or regulated, whether the authorities are centralized or decentralized, whether the public-private partnership is in conflict or cooperation, and whether land use is integrated or separated.

There are many classifications of the types of planning - according to the site, according to the time horizon, according to the scope, according to the specific situation, according to the leading idea set in the planning documents, etc. synoptic, incremental, strategic and business planning, for current and calendar planning, for continuous, situational and crisis planning. The different types of planning documents developed because of the planning process, such as strategies, concepts, plans, programs and projects, are also different.

Regarding the development of the regions, the planning science has proposed various leading concepts to become the basis for their formation and management as separate territorial units. For a long time in Bulgaria, during the so-called socialist period, leading was the concept of localization choice and territorial location of productive forces. In a centralized economy, planning had to answer the question of where it is best to locate new capacity, taking into account factors such as natural conditions and availability of resources, population and skills of the workforce, consumption, infrastructure, transport costs, etc. Thus, a number of industrial zones and agricultural complexes were planned and created, which became attractive 
centers for the development of the regions. The main planning methods were economic-mathematical, incl. production functions and optimization models, which had to give the best solutions in terms of the target function and the restrictive conditions, balance methods, which had to ensure harmonious development and methods for scheduling the works in time, in order to determine calendar schedules.

With the beginning of the democratic changes from the early 90 s, this concept was replaced by another one, namely with the idea that cities should become centers of attraction, attracting the adjacent hinterlands, i.e. less developed nearby territories. The type and content of the regional development planning documents also underwent significant changes - the five-year plans have been replaced by regional and municipal development plans and the transition to seven-year strategic documents. Their development followed the model of Camillus and Datta (Camllus \& Datta, 1991), including the following basic steps, which they call the Integrated Framework of Planning Systems (Integrated Planning Systems Framework - IPSF):

- Environmental analysis;

- Defining goals and objectives;

- Internal analysis (assessment of strengths and weaknesses);

- Formulation and evaluation of alternative strategies;

- Choice of strategy;

- Operational plans and implementation;

- Evaluation of results and feedback.

Quite logically, the new concepts required new planning methods, among which the leading methods were SWOT analysis and its derivatives PEST, PESTEL, etc., the analysis of discrepancies or GAP analysis, matrix methods, incl. Internal and External Factors Assessment Matrices, Strategic Position and Action Assessment Matrix, Quantitative Strategic Planning Matrix (QSPM), etc.

Since 2020, Bulgaria has been talking about a new approach in regional development policy, which has necessitated a change in the system of documents for strategic planning of regional and spatial development, aimed at achieving integrated regional development. Integrated planning, unlike sectorial planning, is a process that brings together different types of sectorial planning at different levels so that strategic decisions can be made and a common vision for resources and their allocation can be reached. It serves as a starting point for institutional initiatives and resource allocation. Within integrated planning, all economic, social, environmental and cultural factors are considered together to guide decision-making on urban planning, land use and public works, transport connectivity, environmental protection and the promotion of sustainable territorial development. This approach comes as a continuation of the ideas of sustainable development, smart growth and inclusive growth. During the new programming period 20212027, the municipalities develop Integrated Development Plans, and the Level 2 regions - Integrated Territorial Development Strategies. Integrated plans must "ensure spatial, temporal and factual coordination and integration of different policies and planning resources to achieve the defined goals for lasting improvement of the economic, social and environmental condition of the municipal territory" (Ministry of Regional Development and Public Works, 2020). Integrated territorial strategies aim at "coordinating the envisages of sectorial strategies and documents at regional level in the fields of economic development, health, education, science, social services, transport, water, energy, broadband, tourism and the environment, and reporting of their regional specificities and territorial dimensions" (Ministry of Regional Development and Public Works, 2020).

At this stage, it is not possible to say whether the new approach to regional planning will achieve its goals. The skepticism is dictated by the results of previous years, during which the widely proclaimed principle of cohesion did not lead to convergence between the main economic and social indicators of Bulgaria with those of developed European countries, nor reduced the internal disparity between planning regions of NUTS 2. In order to restore confidence in planning as a set of management approaches and methods for achieving purposeful development, it is necessary to meet the main challenges facing it, which can be divided into two main groups: challenges arising from the development of science and technology, providing new opportunities for planning and challenges posed by public expectations and needs. The first group of challenges is related to the fact that in the time of rapid development of ICT, planning cannot "stand aside" and not take advantage of their opportunities. It has always been based on the availability of sufficient and reliable information, but now it is possible to process a huge amount of data, which without the use of modern technology could be left out of the attention of planners. It can be said that from "information 
planning" you have to move to "database planning". It is a fact that the data are carriers of information, but here the idea is that the planning solutions would be more adequate if they were based on the processing of large databases, and the new planning systems would be built on the principle of Database management systems (DBMS). Recently, there has been increasing talk about the possibilities of the new revolutionary block chain technology, which began to develop with the advent of crypto currencies. It should not be forgotten that a block chain is actually a system in which transaction records are maintained on several computers that are connected in a peer-to-peer network, i.e. it can be used wherever computer networks have been set up that process large databases. With many new applications built on this technology, various solutions such as cloud storage, payment processing and cybersecurity are offered. The possibilities for creating a block chain in regional planning are great, because here there is no need for discretion of the data of one user for another and there is no limits networking. This kind of planning will make us forget the thick reports with analyzes that suggest the best strategies for a given situation, we will be able to say a priori what we want, and the computers will be the ones to tell us how to achieve it. It can be said that this means moving from "setting goals according to the situation" to "forming a situation subordinate to the goals". The methods of Business Analytics (BA) and Business Intelligence (BI) will be used to support strategic decision-making. Strategic analysis, whether in some models, it precedes the formulation of a vision, mission and the setting of strategic goals or in other models, it follows them, has always been an important stage in the overall strategic planning process. But unlike strategic analysis, which boils down to primary data processing and drawing conclusions to support the choice of development strategies, business analytics focuses on the continuous collection, sorting, processing and study of business data and the use of statistical models and iterative methodologies for converting data into business forecasts. Software is used to extract huge volumes of external and internal data to help managers make decisions. Business intelligence uses the measurement, tracking and calculation of the risk associated with hundreds of strategic and tactical decisions made each day (Borisov, et al., 2020).

The other group of planning challenges is caused by the needs of community in the context of sustainable development. The introduction of any new concepts of planning such as permanent, situational, crisis, strategic, integrated, etc. would not make sense if the results that would satisfy the society were not achieved. The regions in Bulgaria face many problems related to poor infrastructural connectivity, depopulation of villages and towns and concentration of the population in 2-3 large cities, disparities in economic development and living conditions and others. Until now, modern concepts embodied in beautiful slogans have not worked. It is necessary for the goals set in the strategies, plans and programs to lead to clear concrete results, described with appropriate indicators, incl. and sustainability, allowing for continuous monitoring of implementation and public scrutiny. This presupposes that the planning documents are the work of a wide range of specialists and stakeholders, and that there are no objective reasons for political and administrative responsibility for the non-achievement of the set goals.

\section{SUSTAINABLE DEVELOPMENT IN THE CONTEXT OF EUROPEAN REGIONAL DEVELOPMENT POLICY}

Sustainable development is a dynamic process that can hardly be associated with a specific result, but rather with the constant maintenance of balance and improvement and reduction of the detrimental impact of people on nature. In September 2015, the UN General Assembly adopted the program for sustainable development until 2030, respectively the goals for sustainable development to it. This is a plan that covers all aspects of sustainable development in 17 main goals, which can give us a real picture of the desired results, as well as 169 specific goals and 232 indicators. In 2017, two years after the setting of the Sustainable Development Goals, the UN Resolution identifies the specific goals and indicators, and the idea is to make them more achievable. The pursuit of sustainable development is linked to the balancing of three main elements: economic, social and environmental balance. Efforts need to be focused on three levels. First: a global level to ensure better governance, better allocation of resources and more informed solutions to achieve the Sustainable Development Goals. Second: actions at local and regional level, covering changes in policies, funding, institutions and the regulatory framework of governments, cities and local authorities. Third: actions by individuals, youth, civil society, the media, the private sector, academia and other stakeholders to provide a sustainable impetus for change.

European policy is based on the global goals of sustainable development, and in 2019, the European Union adopted the EU Strategic Program for the period 2019-2024 and set priorities to address political, economic and social problems. The main priorities are aimed at:

- Protection of citizens and freedoms - related to the control of the EU's external borders and migration policy, the fight against terrorism, cybercrime, etc .; 
- Creating a strong and viable economy - a sustainable economy through various financial levers, strengthening the euro, investment and industrial policy;

- Building a climate-neutral, green, just and social Europe - an efficient circular economy, efficient use of nature and conservation, transition to renewable energy sources, etc.;

- Promoting European interests and values - a stable foreign policy, a neighborhood policy, European democracy, multilateral cooperation, responsibility for security and defense.

The strategic program is the first step in a process that will be continued by the EU institutions and the Member States. In addition, the European Council will monitor the implementation of these priorities and, if necessary, identify additional common policy guidelines and priorities for achieving sustainable development in line with the EU's strategic approach.

Integrated territorial investments are an adequate tool for the implementation of European regulations in national policy in compliance with the 17 global goals for sustainable development and in coordination and coherence with sectorial and horizontal policies. As part of Bulgaria's commitments for balanced development, a number of strategic documents have been developed, such as: The Integrated Energy and Climate Plan of the Republic of Bulgaria 2021 - 2030 - prepared in implementation of Regulation (EU) 2018/1999 on the management of The Energy Union and climate action; Strategy for sustainable energy development of the Republic of Bulgaria with a horizon until 2050 - with the main priority for the transition to a low-carbon economy, energy security, energy efficiency, liberalization of the electricity and gas markets; National Strategy for Sustainable Development of Tourism in the Republic of Bulgaria 2014-2030 supporting the sustainable development of the tourism industry; National Strategy for Development of Scientific Research in the Republic of Bulgaria 2017-2030; Integrated Territorial Development Strategies for Level 2 Planning Regions (NUTS 2); National Strategy for Demographic Development of the Population in the Republic of Bulgaria 2012-2030; National Disaster Risk Reduction Strategy 2017-2030. Integrated transport strategy in the period until 2030, etc.

The National Development Program BULGARIA 2030 was adopted by the Council of Ministers in 2020 and covers three main strategic objectives, namely: accelerated economic development, demographic growth and the reduction of inequalities. This program builds on the previously adopted National Development Program: Bulgaria 2020. The new Program declares intentions in 5 axes of development and 13 national priorities. All of them are commensurate with the $17 \mathrm{UN}$ goals for sustainable development. Sub-priorities have been added to the Program, and the indicated system of indicators for monitoring the achievement of the objectives is of interest. They make it possible to monitor compliance with the policy pursued, to directly measure progress in the area concerned, to provide aggregated information and to be easily traced. The National Program indicates the current value of each indicator by 2018, and in some of them in 2019, the target value of the indicator, as well as the EU average.

All these documents require a higher degree of specification in terms of their actual implementation. This became possible after the changes in the Regional Development Act in 2020, when the new system of documents for regional development is regulated. The implementation of integrated strategies at NUTS 2 level and integrated development plans at LAU 2 level allow for synergy and cohesion in the implementation of public policies at different levels, administrative bodies and sectors. The integration of sustainable development indicators in the regional development documents largely implies the planning of specific interventions on the ground to be implemented within the programming period 2021-2027.

In this regard, researches by authors such as Bogdanova and Terziev, who examine the strategic and financial framework of interventions in the Centers of Excellence and the Centers of Competence established in Bulgaria to promote the sustainable development of the regions through innovation and science, are of interest. (Bogdanova \& Terziev, Strategic and financial frame of intervention-centers of excellence and centers of competence, 2019). The country's efforts in this direction are entirely in the context of European policy and the objectives of the Operational Program "Science and Education for Smart Growth" (Bogdanova \& Terziev, 2019). The dynamic environment often requires adaptation to new business models to increase the competitiveness of the organization and the capacity to innovate. (Bogdanova, Strekalova, \& Korchagina , 2020) (Bogdanova \& Terziev, 2019).

There is a need for additional actions and policies to be implemented in terms of demographic problems, staff shortages, and the state of agriculture. The fact is that Bulgaria still does not have a national strategy for sustainable development as a separate document, as well as a specialized high-level coordination mechanism in the executive branch, which is responsible for supervising the effective implementation of the sustainable development goals in Bulgaria, incl. and in regional development policies pursued through 
integrated territorial investments.

\section{INTEGRATED TERRITORIAL INVESTMENTS FOR SUSTAINABLE DEVELOPMENT}

Integrated Territorial Investments are seen as a tool to achieve better governance of regional development and increase the impact of public policies. The idea is for more efficient and effective management of the public resources that the EU allocates in order to achieve cohesion. This approach ensures the planning and implementation of multidirectional and cross-sectorial measures.

The applying of the ITI approach requires the development of an integrated planning document for the development of a specific geographical area, i.e. it is necessary to have clearly defined boundaries within which the planning documents with a certain time horizon will be applied. Specific to the approach is that the planning documents imply consolidation of strategic and operational measures, for the implementation of which bodies are institutionalized or powers are delegated. The idea assumes that the geographical area should be in dynamic interaction with the other neighboring territories, thus ensuring multiplication of the impact and connectivity, both interregional and sub-regional.

Hierarchically, the system is decentralized in order to increase the involvement of stakeholders and the delegation of powers to ensure wider application of the bottom-up approach. To some extent, the ITI approach is close to the Community Led Local Development (CLLD) approach, which, based on local capacity and needs, defines measures, finances projects and assesses their impact. The aim is to ensure the most sustainable development of the regions, taking into account local specifics and potential.

Sustainable development, as part of the global doctrine of prudent use, conservation and conservation of natural resources for future generations, finds a place in regional development policy at European and national level. The commitments stem from the 2015 UN Summit on Sustainable Development in New York, which ended with the signing of the final document entitled "Changing Our World: A 2030 Agenda for Sustainable Development" (United Nations, 2015). The objectives included in it, through which the agreed indicators will be achieved, must be reflected in the national strategic and regulatory frameworks, and accordingly in the implemented local policies. In 2017, the Council of Europe highlighted the importance of sustainable development for the EU and the responsibility of Member States to achieve it. Emphasis is placed on the three areas of sustainability - economic, social and environmental, and their achievement must be in a balanced and integrated way. Addressing global challenges and achieving ambitious sustainability goals is only possible by including targets in all national, regional and sectorial policies, backed by the appropriate regulatory framework and capacity.

The integrated territorial investment approach is a key tool in regional development, applied in the process of implementing the sustainable development goals, which provides rational solutions with sustainable results in all areas of public policy (Schönwandt, 1999). It ensures the coordinated implementation of formulated sectorial policies that have supra regional and supra-municipal territorial significance and impact. It requires the participation of stakeholders in the processes of formulating public policies for regional development (Roberts, 2006), as well as dialogue and interaction between administrative units, both from one and from different hierarchical levels. In this way, the process of conducting regional policy is decentralized and the local community is empowered to choose solutions that best meet its needs.

As integrated planning is holistic, it provides an opportunity to find ways to conduct sustainable interventions effectively and efficiently. Integrated territorial investments are a tool for administrative units to exceed their available resources by cooperating both tangible and intangible resources, and with the help of attracted grants to lead to the implementation of initiatives with synergetic territorial effect to sustainable development.

There are five main pillars of integrated territorial investment, which enable the implementation of policies in support of sustainable development. (adapted from (Eggenberger \& Partidário, 2000)):

1. Integration in essence - planning solutions to permanent or changing local problems, as well as problems arising from the specifics of the territory.

2. Integration in methodological aspect - application of economic, social and environmental approaches for planning, analysis and evaluation and use of different ICT applications and combination of sectorial methodologies, approaches, indicators, tools and methods of planning.

3. Integration in procedural aspect - integration of the planning processes and the directions for planning and evaluation through coordination, cooperation and subsidiarity of authorities and stakeholders, observing the expert approach and views.

4. Integration in institutional aspect - definition of rights, responsibilities, commitments, coordination and 
subordination of the public authorities engaged in the implementation of the Integrated Territorial Investments at different hierarchical levels.

5. Integration in the political aspect - mandatory application of the principles of sustainable development as a main guiding principle in public policies and adoption of supporting legislation and political commitment at national, regional and local levels to achieve the goals of sustainable development.

Bulgaria for the first time applies the ITI approach in the regional development documents 2021-2027. This poses a number of challenges, as the change in the approach to regional development planning started in March 2020 with the introduction of methodological guidelines by the Ministry of Regional Development and Public Works. (Ministry of Regional Development and Public Works, 2020) (Ministry of Regional Development and Public Works, 2020). The change concerns both the development of strategies for integrated territorial investments at NUTS 2 level and plans for integrated development of municipalities at LAU 1 level and for sustainable development. Set in a number of normative documents - laws and regulations, the idea of sustainability is implemented in the planning documents for the programming period 2021-2027 in specific indicators for sustainable development.

It is a fact that the applied approaches for regional development in Bulgaria in the two programming periods 2007-2013 and 2014-2020 did not lead to the expected impact and growth. The limited integration and coherence of the interventions, the lack of coordination of efforts at the individual levels, the high degree of decentralization of decisions in the field of regional development have led to partial solutions to community problems and isolated changes, which do not have the expected positive impact on the specific territory and on people's lives. At the same time, the country's commitments to contribute to the achievement of the global goals for sustainable development require the achievement of specific indicators for economic, social and environmental development, which is impossible with the mechanisms applied so far for planning and implementing regional development policies.

Achieving ITI-based sustainable development challenges public authorities to ensure the necessary integration in these five areas. At this stage, the normative base is still incomplete, the methodologies are unknown, the coordination is weak, and the institutionalization is nascent. The planning capacity, as a whole in Bulgaria, is limited and the expertise is insufficient. Consulting companies, often without the necessary expertise, carry out the development of planning documents. The trained planning specialists, who also have capacity in the public sector, are units. The allegations are based on content analysis of documents, incl. and those from public procurement, academic programs, professional biographies, etc. Limited time for adaptation and acquisition of ITI implementation skills by public authorities and consultants, poor knowledge of foreign experience and its automatic application to Bulgarian conditions are risk factors that worsen the prospects for successful results and sustainable development of regional policy in Bulgaria.

\section{DISCUSSION}

Overcoming regional disparities and achieving growth are part of the expectations of the ITI approach. The implementation of synergetic public policies based on the effective management of endogenous factors for development and growth are the basis for the good results achieved in EU countries. At the same time, integration is a complex process that requires complex and timely actions, expertise, coordination and communication, engagement, and all in a suitable regulatory environment and institutional regulation.

Bulgaria, as part of the EU, implements the integrated planning approach and the indicators for sustainable development in the current programming period 2021-2027. So far, the Methodological Guidelines for the Preparation of Integrated Territorial Strategies for the Development of Level 2 Regional Planning Regions (ITSD) for the period 2021-2027 were adopted in 2020, which started the process of their development. Following the amendments to the Regional Development Act in March 2020, the system of strategic planning documents was modified, as ITSD are part of it, combining the current Regional Development Plans and NUTS Regional Spatial Development Schemes 2.

According to the Law on Regional Development, the strategies must contain an indicative list of important project ideas for the region with indicative budgets and implementation schedule. (Regional Development Act, 2020). In this way, it is planned to stimulate the bottom-up approach in identifying needs, development potential and possible solutions. However, the fact that the final version of the six documents has not yet been adopted carries real risks for achieving the objectives. With regard to the existence of a specialized collective body to coordinate actions related to ITI concepts, the Regional Development Act imposes these functions on the Regional Development Councils. In this regard, there are some debatable aspects, mainly regarding the number and competencies of the panel of experts of an advisory nature, involved in the units for mediation, public consultations and pre-selection. 
The commitment of local authorities to develop Integrated Municipal Development Plans in the context of the ITSR also creates a conflict. Many of the plans were adopted without valid documents at a higher level. The dynamics of the planning processes, including the changes in the parameters of the Plan for Reconstruction and Development of Bulgaria, puts many unknowns before the public authorities about the future interventions in the regional development. In addition, the limited expertise in the management of planning processes, the integration of public policies, the mobilization of stakeholders create a sense of difficulty in the programming period 2021-2027.

The transformation of the Bulgarian planning practice towards the new integrated approach for regional development faces a number of challenges. Integrated planning through the ITI approach "is not just a reconfiguration of planning, but a complex of complex interconnections and dependencies that must be analyzed and evaluated in perspective and which are the basis of developed and agreed strategic decisions for regional and local development. "(Parashkevova, 2020). The success of the approach depends on many factors and prerequisites, commented above, which are currently not a fact in the Bulgarian planning practice and which are yet to be created in parallel with its implementation.

\section{REFERENCE LIST}

Bachtler, J., Mendez, C., \& Wishlade, F. (2016). Evolution or Revolution? Exploring New Ideas for Cohesion Policy 2020. Glasgow: University of Strathclyde.

Barca, F. (2009). An agenda for a reformed Cohesion Policy, A place-based approach to meeting European Union challenges and expectation. Brussels: European Comission.

Barca, F., McCann, P., \& Rodríguez-Pose, A. (2012). The case for regional development intervention: Placebased verרsus place-neutral approaches. Journal of Regional Science 52(1):; 134-152.

Bogdanova, M., \& Terziev, V. (2019). Strategic and financial frame of intervention-centers of excellence and centers of competence. International E-Journal of Advances in Social Sciences, (pp. pp. 156-167).

Bogdanova, M., \& Terziev, V. (2019). The Academic Capitalism and the New Business Model of the Universities. Knowledge - International Journal. Scientific papers, (pp. pp. 33-4).

Bogdanova, M., Strekalova, N., \& Korchagina , E. (2020). Business Model Reinventing on the Basis of Innovations: The Russian Company Case. DTMIS '20:Proceedings of the International Scientific Conference - Digital Transformation on Manufacturing, (pp. 1-7).

Bogdanova, M., \& Terziev, V. (2019). Defining the Goals in OP "Science and Education for Smart Growth" in Compliance with the Needs. International E-Journal of Advances in Social Sciences,, (pp. pp. 175184).

Borisov, B., Bogdanova, M., Parashkevova, E., Chipriyanov, M., Lazarova, E., \& Stoyanova, M. (2020). New paradigms in plannining. Rouse.

Camllus, J., \& Datta, D. (1991). Managing Strategic Issues in a Turbulent Environment. Long Range Planning 24, 67- 74.

Czischke, D., \& Pascariu, S. (2015). The Integrated Approach to Sustainable Urban Development in 201420: Implementing Article 7, Final Thematic Report URBACT Study New Concepts and Tools for Sustainable Urban Development 2014-20. URBACT.

Davies, S., Ferry, M., \& Vironen, H. (2016). Regional Policy in Europe Targeting Growth and Inequality. Glasgow: European Policies Research Centre.

Eggenberger, M., \& Partidário, M. (2000). Development of a framework to assist theintegration of environmental, social andeconomic issues in spatial planning. Impact Assessment and Project Appraisal, volume 18, number 3, 201-207.

Faludi, A., \& Peyrony, J. (2011). Cohesion Policy Contributing to Territorial Cohesion - Future Scenarios. European Journal of Spatial Development, Refereed article No. 43.

Ferry, M. (2019). Integrated Territorial Investments as an effective tool of the Cohesion Policy. Retrieved from https://www.europarl.europa.eu/cmsdata/162823/25032019_CONT_Briefing_ITI_Final.pdf 
Ferry, M., Kah, S., \& Bachtler, J. (2018). Integrated territorial development: new instruments - new results?, IQ-Net Thematic Paper 42(2). Delft: European Policies Research Centre.

Gaman, F., Luca, O., Burduja, S., Aldea, M., lacoboaea, C., Petrescu, F., \& Sercaianu, M. (2015). Integrated territorial investments: challenges and opportunities - case study of Romania. WIT Transactions on The Built Environment, Vol 168.

Kociuba, D. (2018). Implementation of integrated territorial investments in Poland - rationale, results, and recommendations. QUAESTIONES GEOGRAPHICAE 37(4).

Ministry of Regional Development and Public Works. (2020). Methodical instructions for development and implementation of Plans for integrated development of the municipality (PIRO) for the period 2021. 2027. Sofia.

Ministry of Regional Development and Public Works. (2020). Methodical instructions for preparation of Integrated Territorial Strategies for Development of the Level 2 Planning Regions for the period 2021-2027. Sofia.

Newman, P., \& Thornley, A. (1996). Urban Planning in Europe: International Competition, National Systems, and Planning Projects. Routledge Camllus \& Datta.

Parashkevova, E. (2020). Integrated planning as a tool for overcoming regional differences. Statistical dimensions of regional differences and inequalities between Northern and Southern Bulgaria. (pp. 59-67). Svishtov: Tsenov.

Regional Development Act. (2020). Retrieved from https://www.mrrb.bg/bg/zakon-za-regionalnoto-razvitie/ (2009). Regions matter: Economic recovery, innovation and sustainable growth. Paris: OECD.

Roberts, P. (2006). Evaluating regional sustainable development: approaches, methods and the politics of analysis. Journal of Environmental Planning and Management 49, 515-532.

Scenarios for Integrated Territorial Investments . (2015). Retrieved from https://ec.europa.eu/regional_policy/sources/docoffic/official/reports/pdf/iti_en.pdf

Scenarios for Integrated Territorial Investments. (2015). Retrieved from https://ec.europa.eu/regional_policy/sources/docoffic/official/reports/pdf/iti_en.pdf

Schönwandt, W. (1999). Grundriss einer Planungstheorie der'dritten Generation. DISP 136/137, 25-35.

Taylor, Z. (2013). Rethinking Planning Culture: A New Institutionalist Approach. Town Planning Review, 84(6).

(2001). Territorial outlook. Paris: OECD.

Tödtling , F., \& Trippl , M. (2005). One size fits all? Towards a dif ferentiated regional innovation policy approach. . Research Policy 34: 1203-1219.

Trusculaski, T. (2020). Integrated Territorial Investments as an Instrument of Urban Policy: The Case of the Bialystok Functional Area. European Reserch Studies Journal, Volume XXIII, Issue 3.

United Nations. (2015). TRANSFORMING OUR WORLD: The 2030 Agenda for Sustainable Development . NY.

Van Der Zwet, A., Bachtler, J., Ferry, M., McMaste, I., \& Miller, S. (2017). Strategies for integrated development: how are ESIF adding value in 2014-20? . European Union.

Van Der Zwet, A., Miller, S., \& Gross, F. (2014). Integrated Territorial Approaches in Cohesion Policy 201420. Strathclyd: European Policies Research Centre. 